$\begin{array}{cc}\begin{array}{c}\text { Yanbu Journal } \\ \text { of }\end{array} \\ \begin{array}{c}\text { Engineering } \\ \text { and Science }\end{array} & \text { Vol. 1, October } 2010(1431 \mathrm{H}) \\ \text { www.yic.edu.sa/yjes }\end{array}$

\title{
DETECTION OF STICK-SLIP OCCURRENCES THROUGH NEAR FIELD NOISE MEASUREMENTS
}

\author{
Nadim A. Emira \\ Department of Mechanical Engineering Technology, Yanbu Industrial College, \\ P.O. Box: 30436, Yanbu Al-Sinaiyah, Kingdom of Saudi Arabia. \\ Tel.+96655915 8242,E-mail:nemira@yic.edu.sa \\ On leave from: Faculty of Engineering, Zagazig University, 44111 Zagazig, Egypt.
}

\begin{abstract}
The present study is concerned with evaluating the pin-on-disk test rig usage and the measurements conducted to recognize the occurrence of the stick-slip phenomenon. The test rig consists of two separate blocks to ensure that the vibration of the elastic disk and emitted noise are completely adverted to friction between the moving pin and stationary steel disk. The occurrence of stick slip is clearly picked up using near field noise measurements. It can be distinguished from the vibration signal as high consecutive spikes, but the existence of such spikes is clearer and more definite in the noise signature.
\end{abstract}

KEYWORDS: Pin on disk, friction, induced vibration, noise, and stick-slip.

\section{INTRODUCTION}

The vibration and noise induced by dry friction are overwhelmed by non linearity factors. One of the main origins of non linearity is the variation in the coefficient of friction. Such variation is attributed to many factors like change of pin velocity, occurrence of stick slip, and change of the acting normal force due to pin vibration in the normal (vertical) direction. The remarkable variation of contacting surface topology due to occurrence of abrasive and adhesive wear has a big contribution to the variation of the friction coefficient. Wave transmission and vibration modes of the disk and pin also have considerable effect on the measured vibration signature. The friction characteristics resulting from the motion of one surface over another can often strongly influence the behavior and operational efficiency of many physical systems. It is often cited that about $40 \%$ of the frictional problems in industries are due to vibrations induced by friction [1-7].

\subsection{FRICTION INDUCED VIBRATION}

Friction-induced vibration, chatter, and squeal are serious problems in many industrial applications. Many experimental and analytical studies have led to insight on the factors contributing to brake squeal or to the improvement of squeal in disk brakes of a specific type or in a particular make and model of automobile. Experimental studies have accumulated a wealth of information about the nature of squeal, the vibration modes therein, the wear of brake components, and frictional interactions in brakes. Analytical studies have provided useful insights into how friction, geometry and dynamics of brake components can lead to squeal or instability in simple models of disk 
brakes. Finite elements have been used to try to extend the insights to more accurate brake models. There are a large number of models devoted to brake squeal.

Early work of Earles and Lee [1] featured experiments in which a disk, contacted by a pin which is supported by a flexible cantilever, is spun at a constant speed. The system stability is dependent on the coefficient of friction. Earles and Badi [2] and Earles and Chambers [3-4] used pin on disk systems in which two pins acted on the disk to investigate and quantify the sprag-slip mechanism for squeal. The investigations performed consisted of examining how the damping influenced squeal. Damping in the pin assembly (corresponding to damping of the brake pad assembly in a disk brake) could enlarge the unstable regions under certain circumstances, while disk damping always reduced such regions.

\subsection{CONTACT MECHANICS}

Ibrahim [5] addressed the problem of friction and contact mechanics. He summarized the principal results pertaining to factors affecting friction between sliding surfaces. He stated that the occurrence of stick-slip is unpredictable and is attributed to the fact that the slope of the friction-speed curve is not constant but varies randomly with contamination, surface finish, misalignment of sliding surfaces, and other factors. In the mechanical systems of vibrations there are three categories: stick-slip, vibrations induced by random surface irregularities and quasiharmonic self-excited oscillations.

Ibrahim et al. [6] measured the average normal and friction forces acting on a friction element, which was in the form of a pin placed in contact with a rotating disk. As the rotation speed and direction of the disk rotation were variable, the tests were performed at constant rotational speeds.
Several interesting features were reported, most notably, neither the normal force nor the kinetic coefficient of friction was constant. In fact, the authors reported that the friction and normal forces acting on the friction element are random and non-Gaussian processes.

Ibrahim [7] has discussed the relationships between the results of [6] and role of random vibrations in the generation of brake noise.

\subsection{FRICTION INDUCED NOISE AND VIBRATION}

Considering the acoustics of friction-induced vibration, an illuminating discussion has been reported by Akay [8]. By exposing many of the topics common to both fields, the modeling of friction induced vibrations and friction damping in mechanical systems requires an accurate description of friction for which only approximations exist.

Chan et al. [9] presented a study on brake squeal which is based on the splitting of the frequency of the doublet modes in the symmetric disk when a friction force is applied; the splitting could lead to flutter which is associated with brake squeal. The study considered a clamped elastic annular disk which is loaded, at a discrete number of points, by a tangential follower force traction related to the normal pressure by the coefficient of friction.

Mottershead and Chan [10-11] addressed the tendency of a disk to generate noise when the natural frequencies of in-plane and bending vibrations are close to each other. In addition self-excited vibrations of a circular plate with friction forces acting on its edge are considered to model squeal in drum brakes.

Based on experimental data, Emira [12] presented a three-degree-of-freedom model of a rotating pin-on-disk system to investigate the effect of varying both the normal force and the system stiffness parameters on the system response in three directions (namely 
normal, tangential and rotational) at different speeds. Research results stated that at any specific speed, increasing the normal force increases the calculated system response. Also, increasing the pin velocity increases the amplitude of system response in the three directions. The change in amplitude of system response is inversely related to changes in stiffness parameters of the system.

\subsection{STICK-SLIP AND FRICTION MODELS}

From a technological standpoint, one of the most important roles of tribology is to provide a smooth relative motion of contacting surfaces. An intermittent motion of surfaces (termed stick-slip) leading to the decreased functional status of a mechanical system is a nuisance, which should be predicted and prevented in its design stage. The fundamental framework to prevent stick-slip has recently been constructed through dimensionless analysis of its occurrence limit [13-14]; it is an undeniable fact however that the problems caused by stick-slip are diverse, which necessitates the studies of the individual problems. Maegawa and Nakano [15], investigated the mechanism of stick-slip associated with surface waves. Surface waves are likely to occur for low contact load and high driving speed, which apparently contradicts the tendency of general stick-slip. The experimental tests on a pin-on disk type sliding system by Dweib and D'Souza [16] have indicated that, for a constant sliding speed, the friction force depends on the normal load. According to the value of the normal load, there are four different regimes; namely, steady-state, non-linear, transient friction, and self-excited vibration regions.

Kinkaid et al. [17] presented a detailed revision of the pin on disk friction models. A revision of most of the models that have appeared in the literature is demonstrated. The inter-relationships between such models are highlighted. In the models, a linear stability analysis was performed in order to predict the onset of instability, which has been correlated to the occurrence of squeal.

For the typical test rigs usage, such as those used by [18] and [19], the effect of the disk elasticity is not included since the disk is usually supported to a heavy rigid base. Fig. 1 shows a typical pin on disk arrangement. In such test rigs, the frame used supports all parts: the pin arrangement (which is fixed), driven disk and driving motor. Thus, measured vibration (of the pin) would include traces due to vibration of the driving arrangement.

The present paper is concerned with building a pin-on-disk test rig and evaluating its performance. Conducting a series of tests under different conditions of pin speed, applied load, and pin material and recording the emitted noise is one of the research objectives. The experimental tests led to recognizing the occurrence of stick-slip phenomenon.

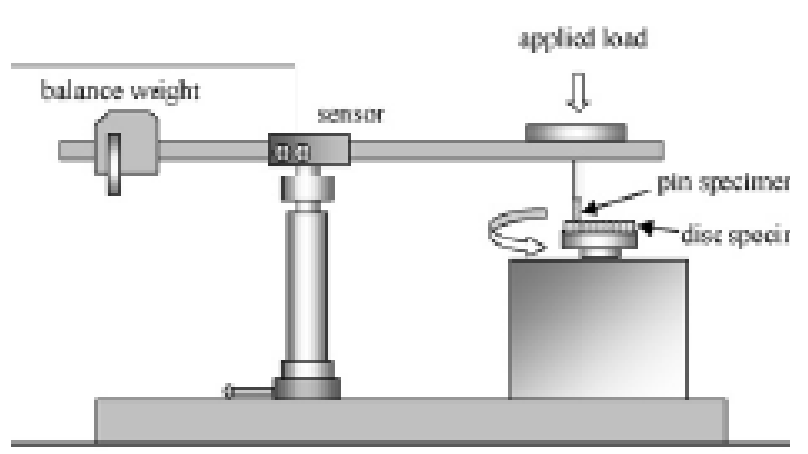

Fig. 1. A typical pin on disk test rig.

\section{THE TEST RIG}

The objective of the test rig is to enable the measurement of both noise and vibration of the disk in three perpendicular axes induced by friction. The directions are: vertical/ normal (perpendicular to disk surface), horizontal (tangential to the locus of the pin), and radial (perpendicular to the tangential 
direction, in plane of the disk surface). Fig.2 shows the test rig arrangement.

The rig; shown in Fig.2, is installed in an anechoic chamber. It constitutes a sliding pin attached to a rotating pulley; whereas the friction disk $(\Phi 300 \times 15[\mathrm{~mm}])$ is fixed. A steel cube is attached to the fixed disk, on which accelerometers are attached in the required direction (three perpendicular axes). A $1 / 2$ inch $\mathrm{B} \& \mathrm{~K}$ microphone is fixed near to the accelerometer position $(2[\mathrm{~cm}]$ apart $)$ and is $3[\mathrm{~cm}]$ apart from the locus of rotation of the moving pin. It is directed radially towards center of rotation.

The testing apparatus is designed to study the friction-induced vibration of the disk at practical loads and speeds. Loads varying from $25[\mathrm{~N}]$ to $75[\mathrm{~N}]$ applied on the pin in the vertical direction, can be tested. The present design also allows testing four pin linear velocities $2,2.6,4$ and $5.2[\mathrm{~m} / \mathrm{s}]$.

The pin, fixed to a pulley, is belt driven using a $1.1[\mathrm{~kW}]$ electric motor. The pulley arrangement includes a greased sliding bearing to minimize vibration. Different from most of the reported pin on disk test rigs, in which the rotating plate is directly fixed on the motor shaft, the present test rig incorporates two separate heavy blocks supporting the test rig. On the first one, the disk and pin arrangement is fixed. The second block is used to hold the driving motor. The arrangement ensured negligible vibration transmitted to the disk from all other sources but the pin.

The measured vibration and noise signals, under no load operation, show no (negligible) trace due to the driving system. Therefore, the measured vibration and noise signals are due to the interaction between the moving pin and the fixed disk.

The normal load is changed using steel plates bolted to the pulley driving the pin.
Measuring the vibration of the disk in the three perpendicular axes is enabled through fixing a steel cube, of $15[\mathrm{~mm}]$ side length, to the plate.

A 2.6[gm] B\&K accelerometer type 4375, and $4.78[\mathrm{mV} / \mathrm{g}]$ sensitivity is used for picking up the disk vibration, and a B\&K microphone type 4189 is used for recording the generated noise signal. An infra red diode with emitter and acceptor is used to pick up a timing signal. It should always be remembered that the measured vibration signal, picked up at a specific fixed location on the disk, is due to excitation induced by friction of the pin at a point somewhere on its locus.

The signal from the infra red diode, representing the timing and triggering signal, is fed directly to a four channel Tektronix digital oscilloscope type TDS200. The signals from the accelerometer and the microphone are fed to the oscilloscope through two B\&K charge amplifiers. The acquired signals are transferred to a computer in both photographic and digital forms for storage and further analysis.

A sampling rate of 25000 [sample/s] is used. This ensures free of anti-aliasing amplitudes up to a frequency of $6[\mathrm{kHz}]$. The three used pins are, steel $(H . R=99.67)$, copper $(H . R=98)$ and aluminum $(\mathrm{H} . \mathrm{R}=96.83)$.

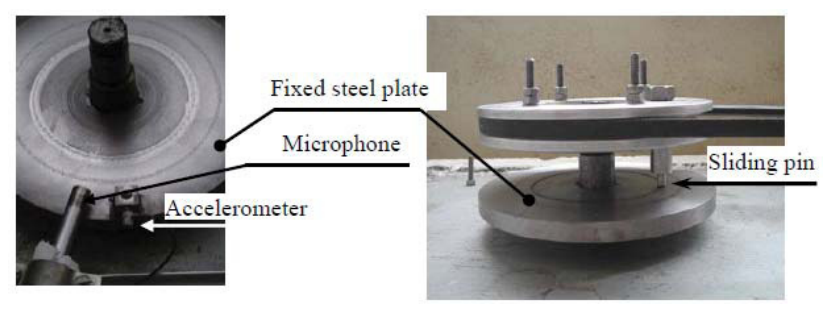

Fig. 2. Test rig arrangement. 


\section{RESULTS AND DISCUSSIONS}

The investigation into friction induced noise and vibration is based on using a fixed elastic steel disk in contact with a moving pin. The effects of changing the contact parameters such as: the pin material, pin speed, and normal load, on the disk vibration and emitted noise are discussed.

Measurements are conducted three times for each test condition. Small variations; which were neglected, in the amplitude of vibration were noticed in cases stick-slip phenomenon was not detected. In such case, the first measurement is reported. In such cases where stick-slip phenomenon is detected, the variations in amplitudes of the spikes resulting from the slipping of the pin are appreciably varying; hence, the three measured vibration signals were averaged and reported.

In all figures, the vertical axes represent the vibration amplitude in $[\mathrm{g}]$ around $(10 \mathrm{~m} / \mathrm{s} 2)$.

The use of vibration spectrum would reveal the frequency contents of the signals, but would not show the start of the stick or the slip events. The only way to see the occurrence of these events is by means of using time signatures.

\subsection{EFFECT OF PIN MATERIAL ON INDUCED DISK VIBRATION}

Three pins of the same geometric shape, but of different materials are used. The used pin's materials are steel, copper and aluminum. Fig.3 shows a comparison between the disk vibration, measured in the vertical direction, induced by friction between the fixed steel disk and the moving pins at pin's linear velocity of $5.2[\mathrm{~m} / \mathrm{s}]$. The Fig. shows that, at a specific speed, the disk induced vibration because of friction is high for the steel pin and low for the copper pin.

\subsection{EFFECT OF PIN SPEED ON INDUCED DISK VIBRATION}

Fig. 4 shows the disk vibration, measured in the vertical direction, due to the moving steel pin at two different pin's speeds, namely $4[\mathrm{~m} / \mathrm{s}]$ and $5.2[\mathrm{~m} / \mathrm{s}]$. The same comparison, when held between the copper and aluminum pins, shows the same attitude. In general, increasing the pin velocity increases the amplitude of vibration in the specific direction.
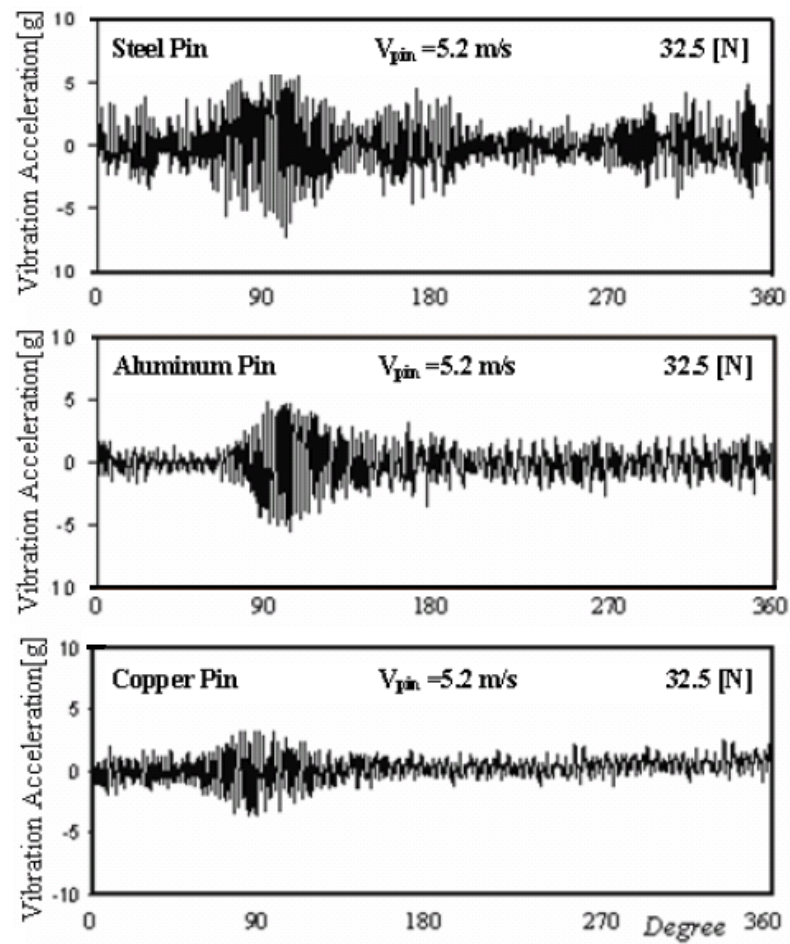

Fig. 3. Effect of varying the contacting pin on the vertical vibration of the disk at pin velocity of $5.2 \mathrm{~m} / \mathrm{s}$ and $32.5 \mathrm{~N}$ normal forces.

\subsection{EFFECT OF NORMAL LOAD ON INDUCED DISK VIBRATION}

Fig. 5 shows the vibration in the vertical direction for the aluminum pin, at a pin velocity of $5.2[\mathrm{~m} / \mathrm{s}]$ at different normal loads. The Fig. shows that the vibration usually increased with increasing the applied normal force. The same conclusion typically applies for all cases. 


\subsection{COMPARISON BETWEEN INDUCED DISK} VIBRATIONS IN THE THREE DIRECTIONS

Figure 6 shows a typical comparison between the induced vibration signals measured in the three perpendicular directions at a given speed and normal load.

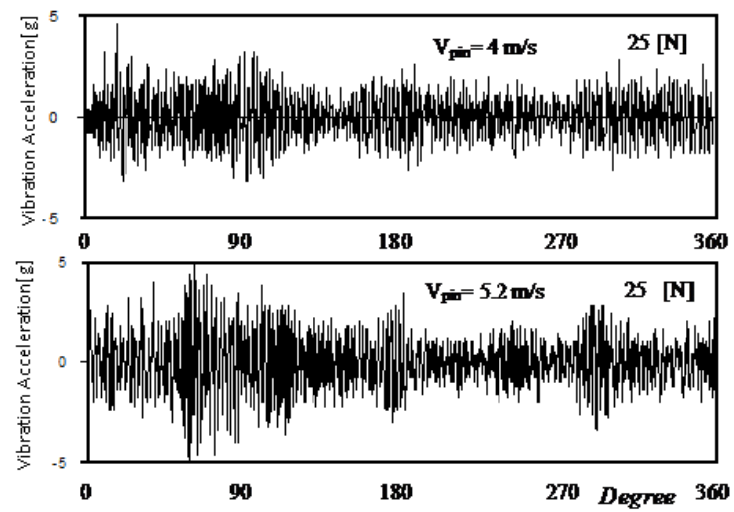

Fig. 4. Effect of varying the steel pin velocity on the vertical vibration of the disk; at the same normal load $(25 \mathrm{~N})$.
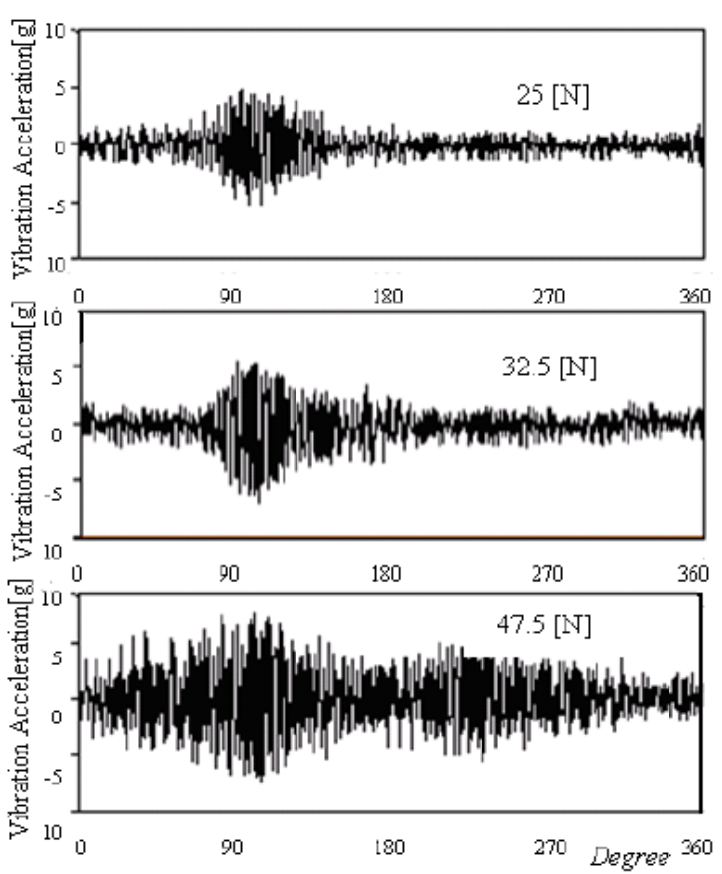

Fig. 5. Measured vertical vibration of the disk using Aluminum pin with linear velocity of $5.2 \mathrm{~m} / \mathrm{s}$ (at different applied normal forces)

Normally, the vibration levels in the vertical direction are higher than that in the horizontal direction. However, the level of the horizontal vibration is higher than that in the radial direction.

\section{RECOGNITION OF STICK-SLIP:}

Simultaneous measurement of the disk vibration and the near field friction induced noise reveal the instant when the stick-slip phenomenon occurs. At that moment, the induced noise is zero. That moment is not clearly identified on the vibration signal. This is attributed to the fact that the disk will continue to vibrate even though the exciting friction force is momentarily zero. Occurrence of stick phase will momentarily induce no noise since there is no friction between the pin and the disk.
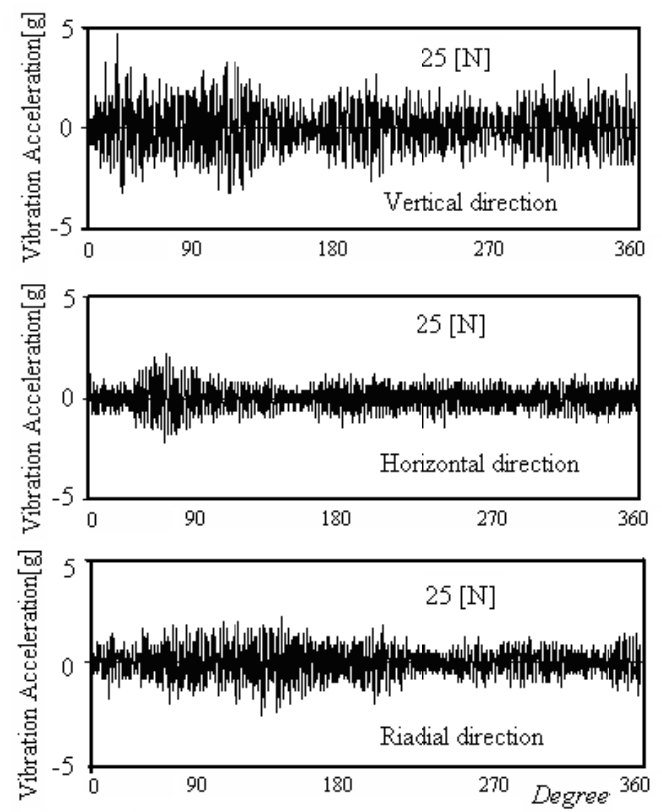

Fig. 6. Comparison between disk vibration in the three directions, when the Steel pin is moving at a velocity of $4[\mathrm{~m} / \mathrm{s}]$; at $25[\mathrm{~N}]$ normal force

Figure 7 shows both the measured vibration amplitude in $[\mathrm{g}]$ and noise signal (sound pressure level) in $[\mathrm{dBA}]$, on the same time basis for the steel pin at linear pin's velocity of $5.2[\mathrm{~m} / \mathrm{s}]$ and normal load of $40[\mathrm{~N}]$. Many stick-slip events can be identified.

The arrows show some of these slipping events producing high spikes on the vibration signature and on the noise signature, too. Between any two successive slip events, there is a stick event, which is recognized by the 
substantially low radiated noise. This figure clearly identifies the occurrence of both stick and slip events.

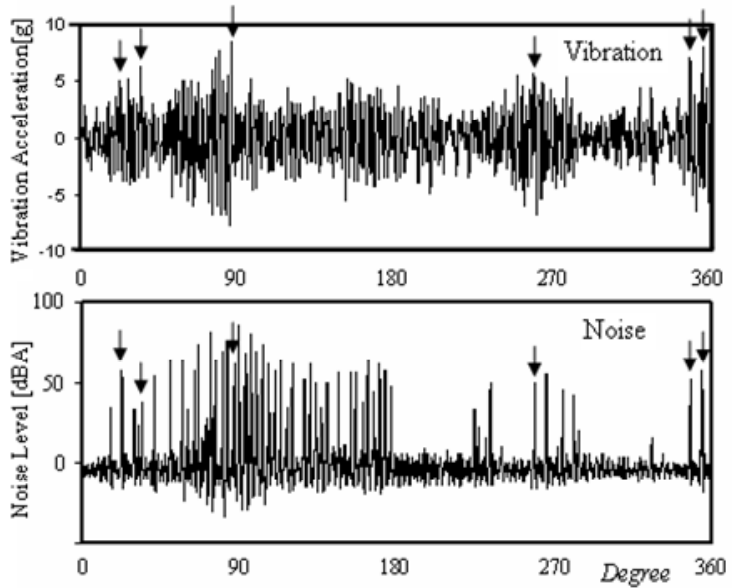

Fig. 7. Measured vertical vibration of the disk and the induced noise (Steel pin, normal load $40[\mathrm{~N}], \mathrm{V}$ pin $=5.2$ $\mathrm{m} / \mathrm{s})$.

The start of the slip event is acknowledged by high spikes on both measured noise and vibration signals. On the other hand, the stick event is recognized by substantially low noise level. During the stick event, the elastic steel disk freely vibrates, therefore vibration level is not reduced greatly (during this period) like the noise level.

\section{CONCLUSIONS}

It is concluded that the vibration amplitude induced by friction is always high in the vicinity of the moving pin. In other words, the phenomenon is a transient one that, in general, has local effect on the disk.

Increasing the normal load and pin linear velocity generally increases the induced vibration amplitude. Vibration amplitude induced by friction between the steel disk and a steel pin is higher than aluminum and copper pins. Also, the amplitude of induced vibration in the vertical direction is the highest compared with that in the horizontal and radial directions.
At high loads or speeds, stick slip phenomenon is predominant. The occurrence of stick slip is clearly identified using the near field measurements of noise signals. It can be distinguished from the vibration signal as high consecutive spikes, but the existence of such spikes is clearer in the noise signature. This is attributed to the fact that noise due to friction momentarily vanishes as stick occurs.

\section{REFERENCES}

[1] S.W.E. Earles, C. Lee, Instabilities arising from the frictional interaction of a pin-disk system resulting in noise generation, Transactions of the American Society of Mechanical Engineers Journal of Engineering for Industry, 98 (1) (1976) 81-86.

[2] S.W.E. Earles, M. Badi, Oscillatory instabilities generated in a double-pin and disk undamped system: a mechanism of disk-brake squeal, Proceedings of the Institution of Mechanical Engineers C 198, (1984) 43-49.

[3] S.W.E. Earles, P.W. Chambers, Predicting some effects of damping on the occurrence of disk-brake squeal noise, in: ASME Dynamic Systems and Control Division, Vol. 1, ASME, New York, (1985), 317-323.

[4] S.W.E. Earles, P.W. Chambers, Disk brake squeal noise generation: predicting its dependency on system parameters including damping, International Journal of Vehicle Design, 8 (1987) 538-552.

[5] R. A. Ibrahim, Friction-induced vibration, chatter, squeal, and chaos; Part I: Mechanics of Friction; Part II: Dynamics and modeling, ASME, Journal of Vibrations and Acoustics, 49. (1992), 107-138.

[6] R.A. Ibrahim, S. Madhavan, S.L. Qiao and W.K. Chang, Experimental investigation of frictioninduced noise in disk brake systems, International Journal of Vehicle Design 23, (2000), 218-240.

[7] R.A. Ibrahim, Friction-induced noise and related problems in automotive brakes, in: S.G. Pandalai (Ed.), Recent Research Developments in Sound and Vibration, Vol.1, Transworld Research Network, Kerala, India, 2002.

[8] A. Akay, Acoustics of friction, Journal of Acoustic Society of America, 111, (2002), 1525-1548.

S.N. Chan, J.E. Mottershead, M.P. Cartmell, Parametric resonances at subcritical speeds in disks 
with rotating frictional loads, Proceedings of the Institution of Mechanical Engineers Part C 208 (C6) (1994) 417-425.

[9] J. E. Mottershead and S. N. Chan, Flutter instability of circular disks with frictional follower loads, Journal of Vibration and Acoustic, 117 (1) (1995) 161-163.

[10] H. Ouyang, J. E. Mottershead, D. J. Brookfield, S. James, and M. P. Cartmell, A methodology for the determination of dynamic instabilities in a car disk brake, International Journal of Vehicel Design 23 (3/4), (2000) 241-262.

[11] M. Nadim Emira, Friction-induced oscillations of a slider: Parametric study of some system parameters, Journal of Sound and Vibration 300 (2007) 916-931

[12] K. Nakano, Two dimensionless parameters controlling the occurrence of stick-slip motion in a 1-DOF system with Coulomb friction, Tribology Letter 24 (2006) 91-98.

[13] K. Nakano, and S. Maegawa, Safety-design criteria of sliding systems for preventing friction-induced vibration, Journal of Sound and Vibration, 324 (2009) 539-555.

[14] S. Maegawa and K. Nakano, Mechanism of stickslip associated with schallamach waves, Wear, 268 (2010) 924-930.

[15] A.H. Dweib and L.T. D'Souza, Self-exited vibrations induced by dry Friction, Part I: Experimental study, Journal of Sound and Vibration, 137, (1990), 163-190.

[16] N.M. Kinkaid, O.M. O'Reilly and P. Papadopoulos, Automotive disk brake squeal, Journal of Sound and Vibration 267, (2003), 105166.

[17] Bin-Bin Jia, Tong-Sheng Li and Xu-Jun Liu, Tribological behaviors of several polymer-polymer sliding combinations under dry friction and oillubricated conditions, Wear 262 (2007) 13531359.

[18] Hozumi Goto and Yoshifumi Amamoto, Effect of varying load on wear resistance of carbon steel under unlubricated conditions, Wear 254 (2003) 1256-1266. 


\title{
كثف حدوث الإلتصاق و الإنزلاق من خلال قياس الضوضاء في مجال قريب
}

\author{
نديم أحمد عميرة \\ العنوان الحالي: قسم الهنسة الميكانيكية - كلية ينبع الصناعية، الدملكة العربية السعودية \\ العنوان الدائم: قسم الهندسة الميكانيكية- جامعة الزقازيق، جمهورية مصر العربية
}

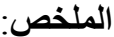

تهتم هذه الدراسة بتحقيق وتقييم الجهاز المستخدم والقياسات التى تمت للتعرف على حدوث ظاهرة الالتصاق و الانزلاق. يتكون الجهاز المستخدم من قطعتين منفصلتين حتى يتم ضمان أن تكون إثنارة الاهتزاز ( المقاسة للقرص الصلب المرن) وكذللك إثارة الضوضاء ناتجتين عن الإحتكاك بين القلم المتحرك والقرص الصلب الثابت فقط. وقد تم تحديد وكثف حدوث ظاهرة الالتصاق والانز لاق بواسطة القياس القريب للضوضاء حيث يمكن كثفها وتمييز ها فى قياس الضوضاء ومن ثم ملاحظتها فى قياس الاهتز از. 